\title{
Mechanical Response Analysis of Double-Column High Piers Impacted by Rolling Stones under the Influence of Pier Height Differences
}

\author{
Wu Liming ${ }^{1}$, Zhang Jianing, , , Wang Zijian², Jiang $\mathrm{Yi}^{2}$ and Yuan Shifeng ${ }^{3}$ \\ ${ }^{1}$ School of Urban Construction Engineering, Chongqing Technology And Business Institute, Chongqing, 401520, China \\ ${ }^{2}$ School of Civil Engineering and Architecture, Chongqing University of Science and Technology, Chongqing 401331, China \\ ${ }^{3}$ A\&T engineering P.C., New York, NY11358, United States
}

Received 10 March 2021; Accepted 22 May 2021

\begin{abstract}
Bridges with double-column high piers are mostly used in mountain areas. This kind of bridge can adapt to complex landform. But the double-column high piers have weak anti-impact capability, which are easily broken under the impact of rolling stones. In order to enhance the performance of bridge piers in resisting against the impact of rolling stones, we conducted the simulation analysis of the mechanical response of double-column high piers. First, we used the explicit dynamic analysis software LS-DNYA to establish the impact model between rolling stones and double-column high piers. Second, we extracted the impact force curve of rolling stones, time history curve of reinforcement stress and change curve of joint displacement at the top of pier to analyze the mechanical response laws of bridge piers under the change of height difference of the pier. Results show that the maximum impact force of rolling stones is not significantly affected by the height difference of the pier. The maximum impact force of rolling stones is mainly influenced by the characteristics of the rolling stones. The height difference of pier has adverse effect on the stress of reinforcement. The maximum joint displacement at pier top is increased with the increase in the height difference of the pier, and the growth rate of maximum joint displacement at the top of piers firstly gradually increased and then declines step by step with the increase in the pier height difference in the direction of impact. The maximum joint displacement at pier top is firstly gradually increased and then reduced as the pier height difference is increased in the non-impact direction. The obtained conclusions provide a significant reference for the design of rolling stone impact resistance of bridges in mountainous areas.
\end{abstract}

Keywords: Double-column high pier; Rolling stone impact; LS-DYNA

\section{Introduction}

Various countries in the world have built expressways or railways to improve traffic conditions and develop transport networks in mountain areas in recent years. However, due to its special topography, there are many high mountains, gorges, river valleys, and deep ravines. Thus, bridges are built to connect traffic routes. The lower part of the bridge mostly adopted double-column high piers, and the heights of the piers are different. In practical design of bridge piers, the solid pier column design without consideration of pier height difference usually involves large excavation and workload filling and occupies excessive mountain resources. The design of double-column high piers considering the height difference can conserve building space and materials. Bridge with double-column high pier constructed in mountain areas considered the pier height difference can improve the construction efficiency and avoid excessive occupation and utilization of mountain resources, such as bridge (Fig.1) in Nan chuan District, Chongqing City, China. It completed the expected function of easing the traffic pressure. In addition, the double-column high piers can better adapt to the special terrain of mountainous mountains with high cliffs and steep canyons considering the design of a certain pier height difference. Due to these characteristics, the design of double-column high piers considering the height difference

*E-mail address: zhang793668206@163.com

ISSN: 1791-2377 @ 2021 School of Science, IHU. All rights reserved.

doi:10.25103/jestr.142.05 has been widely applied in the bridge construction in mountain areas in the world, such as Bai hua Bridge in China (Fig.2). However, this bridge pier has weak antiimpact capability. They can be easily broken under the impact of rolling stones in mountain areas. This shortcoming affected the safety of structures, personnel, and running vehicles along the traffic lines in mountain areas. With the increasing construction of bridges in mountainous areas in recent years, double-column high piers play an increasingly significant role in the traffic route network. The frequency of rocks hitting the bridge is gradually increasing, which further increases the impact on the bridge structure. Therefore, analyzing the mechanical response of bridge piers to the impact of rolling stones under varying pier height difference and formulating the corresponding anti-impact measures is necessary to ensure the safety of pier structures.

Double-column high piers are different from solid piers. Therefore, connecting beams will be built at appropriate positions at the height of the pier to increase the stability of the pier structure. The force characteristics of doublecolumns are quite different from those of general singlepillar piers or double-pillar piers without tie beams. [1] When the double-column high piers are impacted by rolling stones, their mechanical properties and bearing capacities are changed. They suffered from damage and destruction, which seriously affected the normal service functions of bridges and the safety of traffic line [2]. For the bridge pier damage under impact, previous research focused on the 
bridge pier damage under the impact of ships or vehicles [38]. These bridge piers are kept away from mountainous areas and mostly located in cities, with relatively flat terrain and relatively low pier height. The impact mechanisms of ships and vehicles are different from that of rolling stones to some extent [9]. In comparison with other single-column piers or double-column bridge piers with small pier height in mountain areas, double-column high piers are featured with extremely great height and poor rigidity. Thus, they usually experience complicated nonlinear structural changes. The materials undergo great deformations under the impact of rolling stones [10]. The bridge piers undergo reinforcement deformation and concrete damage due to the impact of rolling stones, especially the impact of high-velocity rolling stones. This condition directly degraded the bearing capacity of bridge piers and changed the original stress state of structures above the bridge due to the transmission of impact stress wave transmission of rolling stones. There by affecting the safety of upper structures and the whole bridge [11]. Hence, the research results regarding the ship-pier impact and vehicle-pier impact should not be used in the anti-impact performance evaluation or formulation of antiimpact measures for already built double-column high piers or newly built double-column high piers. With the rapid development of finite element computer technology, software technologies have gradually become a powerful research means adopted by numerous scholars. LS-DYNA is mature and reliable explicit dynamic analysis software widely favored by researchers from all over the world. This software can be used to analyze a series of nonlinear dynamic problems, such as metal forming and manufacturing, rapid collision, and explosion. This software is applicable to the solving and analysis of heat transfer, fluid problem, and fluid-solid coupling problem. The accuracy and reliability of the software analysis results are verified through repeated tests [12-17].

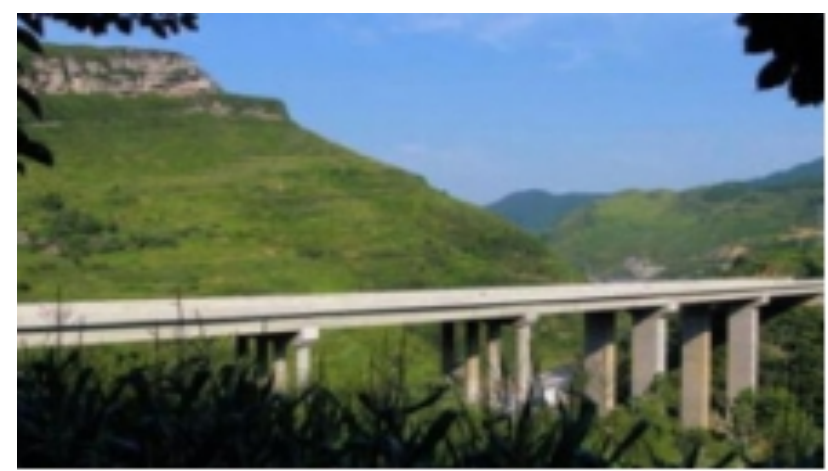

Fig. 1. Changba Bridge

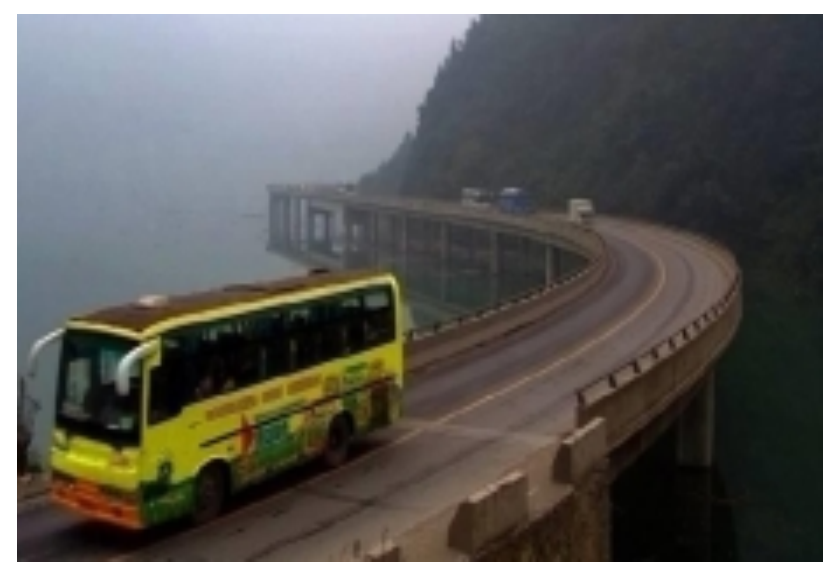

Fig. 2. Baihua Bridge
Many scientific researchers and working personnel have used LS-DYNA dynamic software to investigate the rolling stones-bridge pier collision problems in recent years. However, few studies have focused on double-column high piers. At the same time, the pier height difference has been rarely considered.

The typical double-column high piers in mountain areas in Nan chuan District, Chongqing City, China, were taken as the concrete study objects. On the basis of the existed research results, we use the explicit dynamic analysis software LS-DYNA to simulate the impact process of rolling stones for the double-column bridge piers considering the different pier height. We analyze the mechanical response of the double-column high piers under working conditions. We obtained the pier height-dependent change laws of maximum reinforcement stress and maximum displacement at pier top. The findings can serve as reference for the anti-impact (rolling stones) design of double-column high piers and reinforcement measure design in mountain areas.

\section{State of art}

The impact force of rolling stones is an important basis for the regional protective structural design [18]. The impact force of rolling stones is calculated by referring to the relevant empirical approaches as stipulated in the tunnel specifications in China's highway and railway industries, including the Tunnel Manual in the Railway Industry, the calculation formula for the impact force of rolling stones proposed by Yang[19], and its improved formula. Foreign specifications include semi-empirical and semi-theoretical algorithms, such as the calculation method for the impact force of rolling stones proposed by Japan Highway Public Corporation [20] and that recommended by Swiss Labiouse (1996)[21]. However, the factors considered by these formulas are incomplete. The impact force of rolling stones is affected by complicated factors. Thus, the impact force of rolling stones calculated by these formulas deviates from practical engineering to a certain degree. For instance, Ye compared the existing calculation formulas for the impact force of rolling stones [22] and pointed out the error between the impact force results of rolling stones calculated by the existing calculation formulas and practical engineering results. He found that the results calculated through the Japanese and Swiss formulas accord with the practical engineering by comparatively analyzing the different calculation methods. However, their scope of application is restricted by complex influencing factors. Many scholars have conducted numerous studies to obtain an accurate calculation formula for the impact force of rolling stones. Hou [23] explored the kinetic characteristics of rolling stones and the calculation methods for the impact force of rolling stones by considering the autorotation factor of rolling stones and applied them to the rolling stone induced disaster analysis in practical engineering. However, accurately estimating the shape and size of rolling stones in practical situation is difficult. An assumption applicable to this formula is that the rolling stones are spherical, and the impact force result of rolling stones obtained using this formula is partially large. Richie [24] studied the motion rules of rolling stones. All of the abovementioned studies with respect to the impact force of rolling stones have attached importance on the influences of the characteristics of rolling stones, such as velocity, mass, impact position, 
and shape, on the impact force of rolling stones. The change laws of the impact force of rolling stones with the velocity, mass, and impact position, and the relational expressions of impact force with various factors are analyzed. However, the impact force of rolling stones is affected by the characteristics of the impacted structure, such as the structural form, strength, and material characteristics. Thus, the effect factors of the impact force of rolling stones are incomplete. Different structures present different responses to the impact of rolling stones due to the material and density. Thus, the influence borned by the structures from the impact of rolling stones cannot be ignored.

Therefore, directing at the deficiencies of the existing studies, Changba Bridge in Nanchuan District, Chongqing City, China, was taken as the concrete study object. The mechanical response of double-column bridge piers to the impact of rolling stones under varying pier height difference was studied on LS-DYNA software. The time history curve of the impact force of rolling stones, reinforcement stress strain curve, and displacement change curve at pier top were extracted. The change laws of the maximum response value of reinforcement stress and the maximum response value of displacement at pier top with the pier height difference were analyzed and summarized.

The remainder of this study is organized as follows: Section 3 expounds the parameter determination of finite element modeling. Section 4 proposes the time history curve of the impact force of rolling stones, reinforcement stressstrain curve, and displacement change curve at pier top and analyzes the results. Section 5 summarizes the study and provides the relevant conclusions.

\section{Methodology}

\subsection{Engineering background}

The prototype simulated in this study was the doublecolumn high piers of Changba Bridge located in Nanchuan District, Chongqing City. The bridge was an integral type bridge, where the left and right breadths were $12 \mathrm{~m}$, the overall bridge width was $24 \mathrm{~m}$, the numbers of left and right bridge spans were 5 , and the bridge length was $220 \mathrm{~m}$. The layout drawing of bridge elevation is shown in Fig.3, where No. 1 and No. 2 bridge piers of the bridge were hollow thinwalled piers with the pier height of 47 and $60 \mathrm{~m}$, respectively. The No.3 bridge pier of the continuous beam bridge was a double-column high pier with a tie beam structure, whose pier height of $40 \mathrm{~m}$, and the No.4 bridge pier of the continuous beam was a double-column pier, with the pier height of $14 \mathrm{~m}$. The double-column high pier (No.3 bridge pier) with the height of $40 \mathrm{~m}$ was numerically simulated. The bridge pier had a circular cross section with the diameter of $2.3 \mathrm{~m}$, and the height of beam was $2.2 \mathrm{~m}$. The profile map of No.3 bridge pier is shown in Fig.4. The concrete strength grade of bridge piers was C50. The thickness of concrete protective cover was $50 \mathrm{~mm}$. The reinforcement strength grade was HRB335. The diameters of longitudinal bar and stirrup of bridge piers were 28 and 12 $\mathrm{mm}$, respectively. A $2 \mathrm{~m}$ reinforced section was arranged at the joint between bridge pier and bent cap and that between bridge pier and pile foundation, and the stirrup spacing was $10 \mathrm{~cm}$. The No. double-column high pier with $40 \mathrm{~m}$ in height was selected for the simulation study.

\subsection{Finite element modeling}

In the finite element simulation of double-column high piers under the impact of rolling stones in mountain areas, solid 164 solid elements were selected as the concrete elements. We selected the Holmquist-Johnson-Cook model [31-36] to study the impact problem as the material constitutive model. The reinforcement elements were LINK160 elements. The material model was bilinear kinematic hardening elasticplastic model, Solid164 solid elements were selected as the rolling stone elements, and the material constitutive model was a rigid model. The material parameters of concrete, reinforcement, and rolling stones are follows:

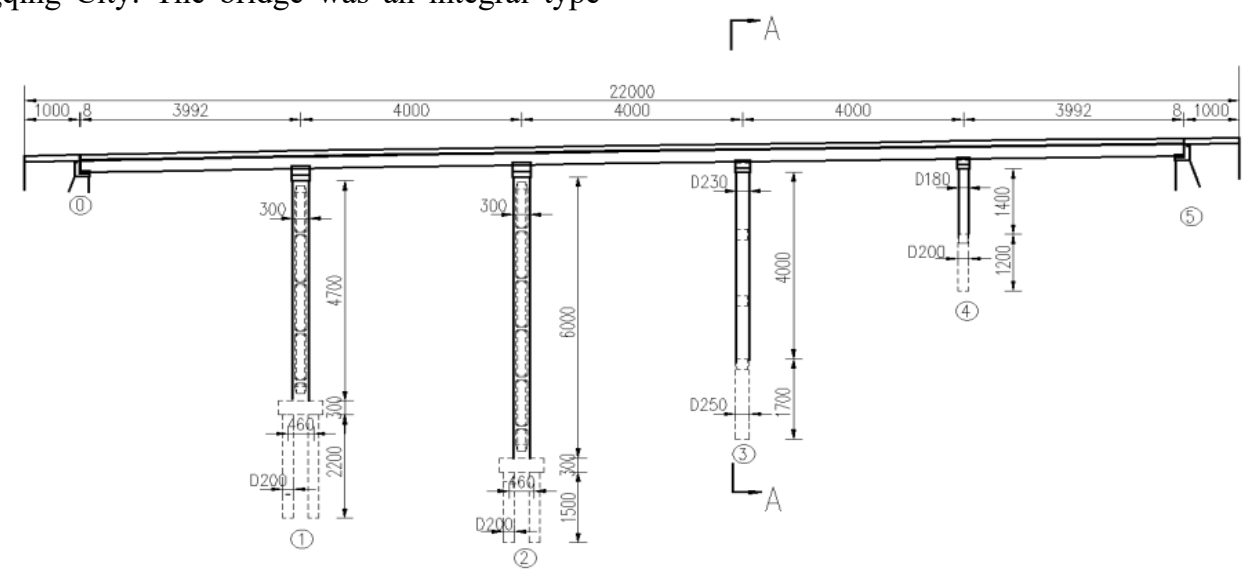

Fig.3. Layout Drawing of Bridge Elevation (unit: cm)

Table 1. HJC material constitutive parameters of double-column high pier concrete

\begin{tabular}{|c|c|c|c|c|}
\hline$\rho_{0} / \mathrm{g} \cdot \mathrm{mm}^{-3}$ & $\mathrm{G} / \mathrm{GPa}$ & $\mathrm{f}^{\prime} / \mathrm{MPa}$ & $\mathbf{A}$ & B \\
\hline 0.0025 & 19.33 & 58 & 0.79 & 1.6 \\
\hline $\mathrm{C}$ & $\mathrm{N}$ & $\mathrm{S}_{\max }$ & D1 & D2 \\
\hline 0.007 & 0.61 & 7.0 & 0.04 & 1 \\
\hline$\varepsilon_{\mathrm{fmin}}$ & $\mathrm{T} / \mathrm{MPa}$ & $\mathrm{P}_{\text {crush }} / \mathrm{MPa}$ & $\mu_{\text {crush }}$ & $\mathrm{P}_{\text {lock }} / \mathrm{GPa}$ \\
\hline 0.01 & 5.8 & 12 & $0.829 \mathrm{e}-3$ & 0.8 \\
\hline$\mu_{\text {lock }}$ & $\mathrm{K}_{1} / \mathrm{MPa}$ & $\mathrm{K}_{2} / \mathrm{MPa}$ & $\mathrm{K}_{3} / \mathrm{MPa}$ & $\dot{\varepsilon}_{0}$ \\
\hline 0.1 & 85 & -171 & 208 & 1 \\
\hline
\end{tabular}




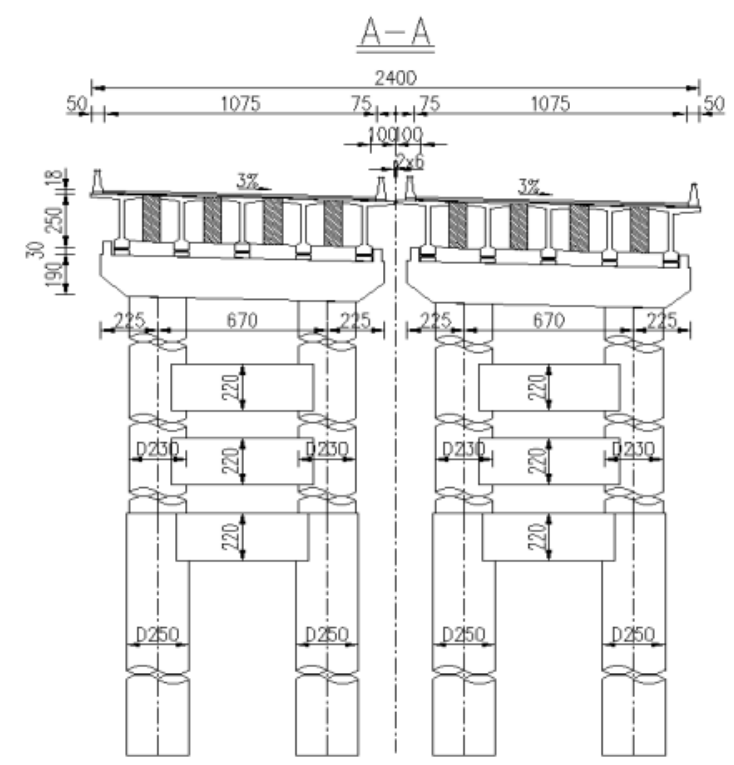

Fig.4. Profile Map of NO.3 Bridge Pier (unit: $\mathrm{cm}$ )

Table 2. Material parameters of reinforcement constitutive model

\begin{tabular}{c|c|c|c|c|c|c|c|c|c}
\hline Project & $\rho_{0} / \mathrm{g} \cdot \mathrm{mm}^{-3}$ & $\mathrm{E} / \mathrm{GPa}$ & $\mathrm{U}$ & $\sigma_{0} / \mathrm{MPa}$ & $\mathrm{E}_{\mathrm{t}} / \mathrm{MPa}$ & $\mathrm{C} / \mathrm{S}^{-1}$ & $\mathbf{P}$ & $\mathbf{f}_{\mathrm{s}}$ & $\boldsymbol{\beta}$ \\
\hline reinforced & 0.0078 & 206 & 0.3 & 335 & 1.2 & 40 & 5 & 0.2 & 0 \\
\hline
\end{tabular}

Table 3. Rolling stone material parameters

\begin{tabular}{c|c|c|c}
\hline Project & $\rho_{0} / \mathrm{g} \cdot \mathrm{cm}^{-3}$ & $\mathrm{E}_{\mathrm{s}} / \mathrm{GPa}$ & $\mathrm{U}$ \\
\hline Rolling stone & 2.3 & 2.63 & 0.22 \\
\hline
\end{tabular}

In the modeling process, the pier concrete model was established in three separate parts: concrete protective cover $(25 \mathrm{~mm})$ in outer ring, concrete protective cover $(25 \mathrm{~mm})$ in inner ring, and concrete column (radius: $1.15 \mathrm{~m}$ ) in inner ring, to display the concrete damage conveniently. The mesh size of the circular cross section of bridge pier was determined as $100 \mathrm{~mm}$ in accordance with the spacing of longitudinal reinforcement to facilitate the establishment of longitudinal bars in the mesh generation for the cross section of pier concrete. In the mesh generation for the elevation of pier concrete, local mesh refinement was performed within the $2 \mathrm{~m}$ range of pier bottom and top, and the mesh size was $100 \mathrm{~mm}$. No mesh refinement was conducted within the $2 \mathrm{~m}$ pier concrete zones at the bottom and top of bridge piers. Thus, the meshes were enlarged to $200 \mathrm{~mm}$ to facilitate the follow-up stirrup establishment in the refinement zone and reduce the model calculation time. The size of pier concrete was identical with the reinforcement size. The finite element models of rolling stones and bridge piers after the mesh generation are shown in Fig.5. The simulation calculation time was set as $\mathrm{t}=0.1 \mathrm{~s}$.

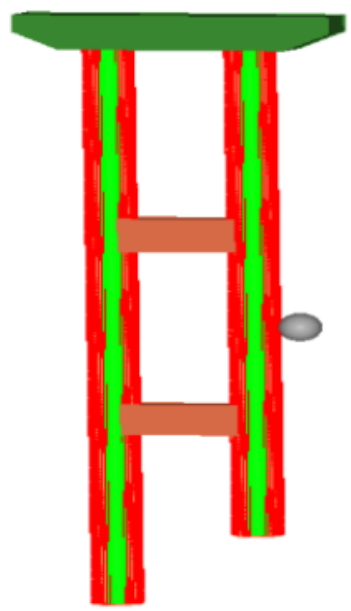

(a) Physical models of rolling stones and bridge piers

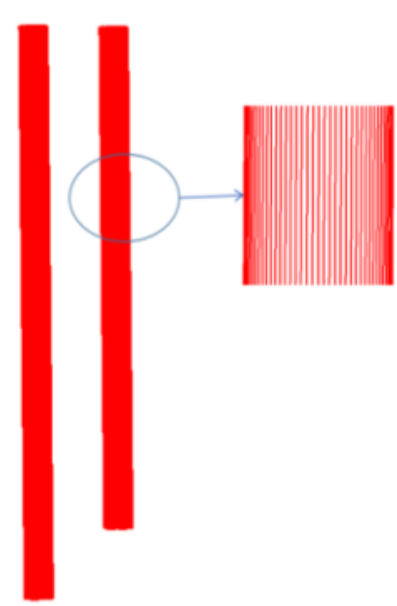

(b) Longitudinal bars

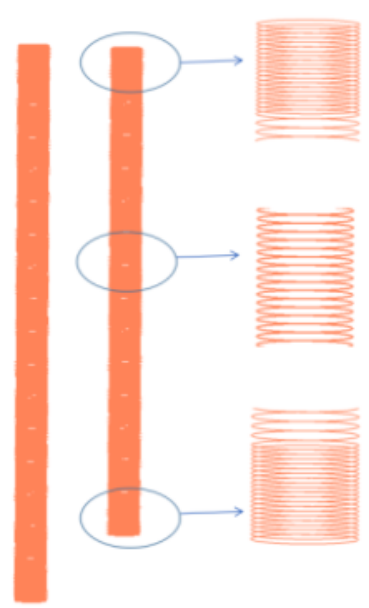

(c) Stirrups 


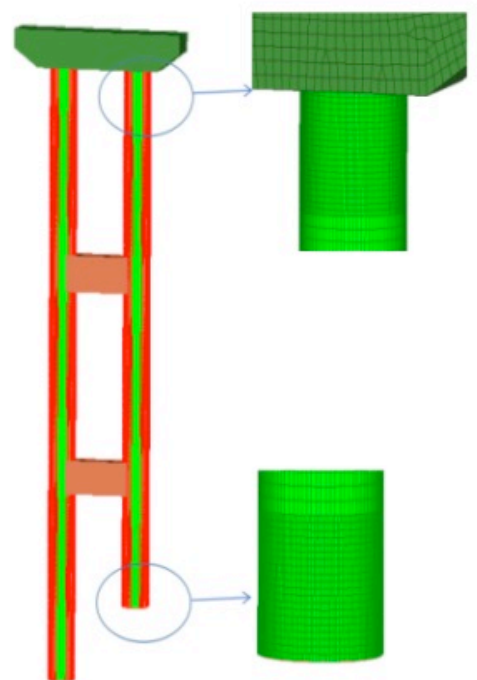

(d) Pier concrete

. 5. Finite Element Models of Rolling Stones and Bridge Piers

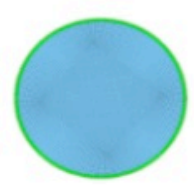

(e) Rolling stone

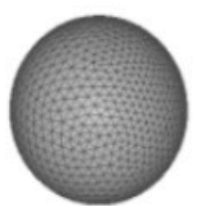

(f) Rolling stone

\subsection{Model working conditions}

The simulation was conducted considering the height differences in the impact direction and those differences are listed in Table 4 .

Table 4. Working conditions of different pier height

\begin{tabular}{c|c|c|c|c|c}
\hline Working condition & Mass(t) & Speed(m/s) & Impact position & Pier structure form & Pier height difference \\
\hline $\begin{array}{c}\text { Operating condition 1 } \\
\text { (basic operating } \\
\text { condition) }\end{array}$ & 5 & 10 & Middle & Double-column high piers \\
$\begin{array}{c}\text { Operating condition 17- } \\
25\end{array}$ & 5 & 10 & Middle & Double-column high piers & Impact direction difference 1-9 m \\
$\begin{array}{c}\text { Operating condition 26- } \\
34\end{array}$ & 5 & 10 & Middle & Double-column high piers & $\begin{array}{c}\text { Non-impact direction difference } \\
1-9 \mathrm{~m}\end{array}$ \\
\hline
\end{tabular}

\section{Result Analysis and Discussion}

\subsection{Impact force analysis of rolling stone}

The time history cure of the impact force borne by the double-column high piers from the rolling stones under the basic working conditions was extracted, which is shown in Fig.6.

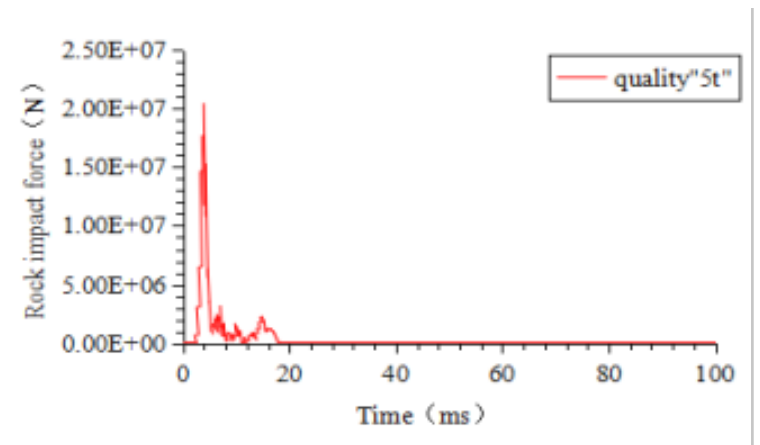

Fig. 6.Time History Curve of Impact Force under Basic Working Conditions

The impact force of rolling stones reached the maximum value of $20.37 \mathrm{MN}$ at $\mathrm{t}=3 \mathrm{~ms}$. After the maximum value, the impact force reduced to a small nonzero value at $\mathrm{t}=4 \mathrm{~ms}$ and then presented an oscillating variation trend with the compression of rolling stones and pier concrete. When the rolling stones no longer contacted the concrete, the impact force became zero, that is, the impact force of rolling stones was $0 \mathrm{MN}$ after $\mathrm{t}=10 \mathrm{~ms}$ in the time history curve chart. The reason to the impact force did not rapidly decline to 0 after reaching the maximum value was the interaction between the rolling stones and bridge pier concrete. Specifically, the motion acceleration and velocity direction of rolling stones faced the impact direction before the rolling stones impacted the pier concrete. The bridge piers generated a reactive force under the impact of rolling stones when the rolling stones impacted the pier concrete due to the impact deformation resistance of the pier concrete itself. Thus, the motion acceleration of rolling stones faced the reverse direction of impact direction. However, the rolling stones moved toward the impact direction instantaneously when bearing the reactive force of bridge piers due to the inertia. The kinematic velocity was rapidly reduced. When the impact force of rolling stones exceeded the concrete bearing capacity, the concrete was damaged and fell off, leading to the change in the reactive force generated to the rolling stones and affecting the kinematic velocity of rolling stones. Hence, the impact force of rolling stones declined from the maximum value to a small nonzero value, as shown in the time history curve of impact force. Subsequently, it was changed in an oscillating manner with the compression of rolling stones-bridge pier concrete until the rolling stones no longer contacted the concrete, and the impact force became zero.

Above analysis indicates that the impact force reaches the maximum immediately after the concrete of double column high pier structure is impacted by rolling stones. The impact force rapidly declined to a small nonzero value after reaching the maximum value, and then presented an oscillating change with the compression of rolling stones and concrete due to the interaction between rolling stones 
Wu Liming, Zhang Jianing, Wang Zijian, Jiang Yi and Yuan Shifeng/

Journal of Engineering Science and Technology Review 14 (2) (2021) 34 - 43

and pier concrete, where the impact force was smaller than that at the moment of impact. When the rolling stones no longer contacted the pier concrete, the impact force became 0 . Therefore, focusing on the maximum impact force of rolling stones is necessary.
The maximum attack force values of rolling stones under different pier height differences were extracted, which is shown in Fig.7. The maximum impact force of rolling stones was mostly unaffected by the pier height difference.

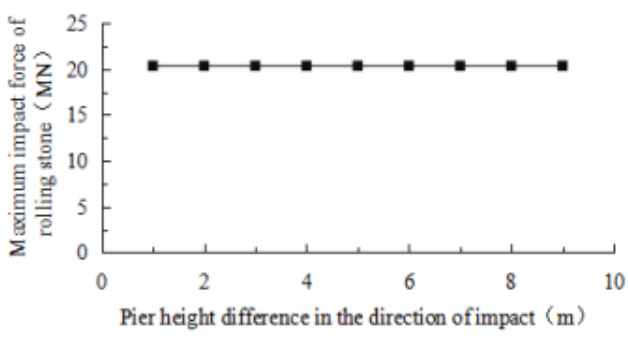

(a)

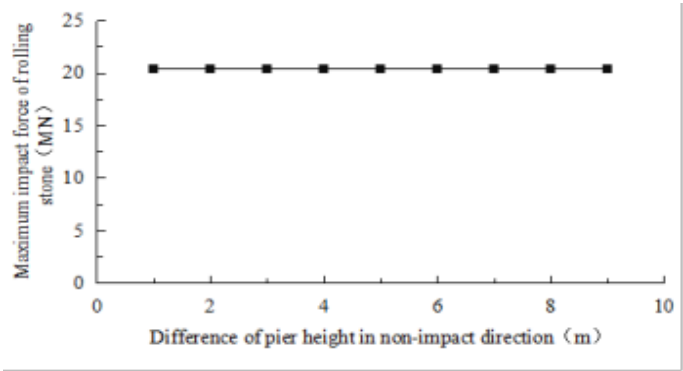

(b)

Fig.7. Maximum Impact Forces of Rolling Stones under Different Pier Height Differences

\subsection{Time history analysis of reinforcement stress}

The reinforcement stress distribution in the double-column high pier under the impact of rolling stones can reflect the part of pier reinforcement susceptible to the impact of rolling stones. The stress nephograms of longitudinal bar and stirrup in the bridge pier under the basic working conditions at typical time are shown in Fig. 8 and Fig.9.

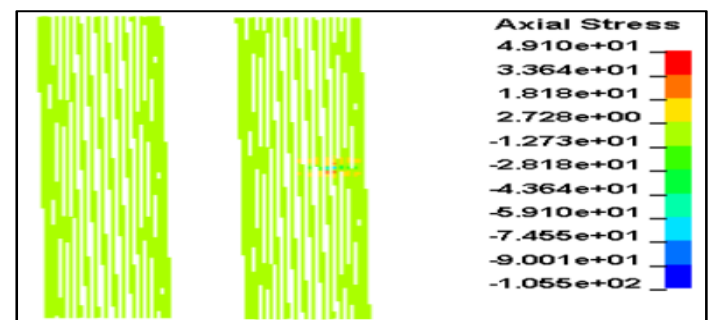

(a) $\mathrm{t}=3 \mathrm{~ms}$

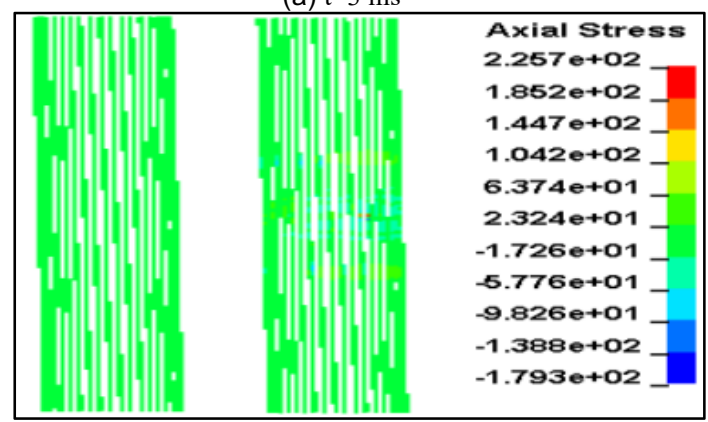

(c) $\mathrm{t}=7 \mathrm{~ms}$
Axial Stress

$2.267 e+02$

$1.852 e+02$

$1.042 e+02$

$6.374 e+01$

$2.324 e+01$

$9.826 e+01$

$+02$

Fig.8.Stress Nephogram of Longitudinal Bars in Bridge Pier under Basic Working Conditions

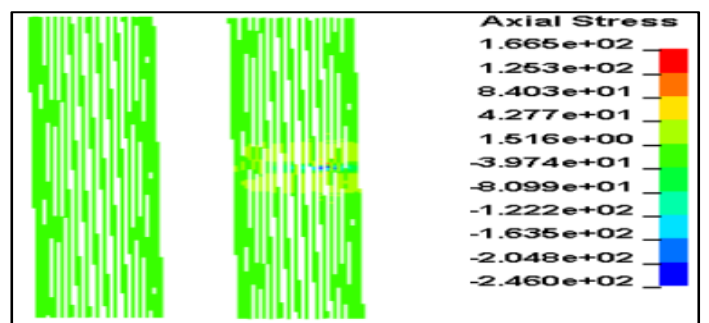

(b) $\mathrm{t}=4 \mathrm{~ms}$

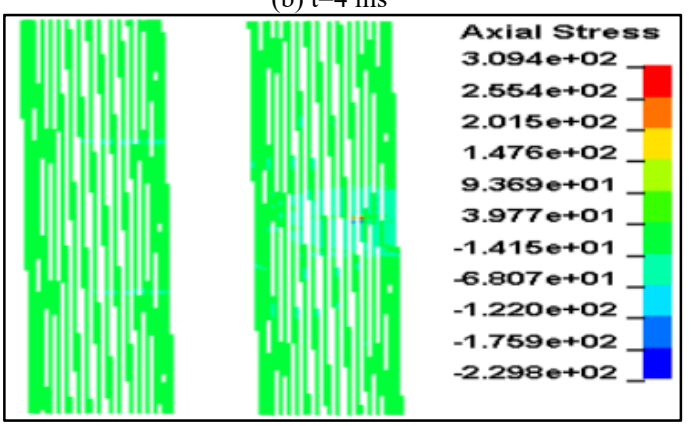

(d) $\mathrm{t}=10 \mathrm{~ms}$

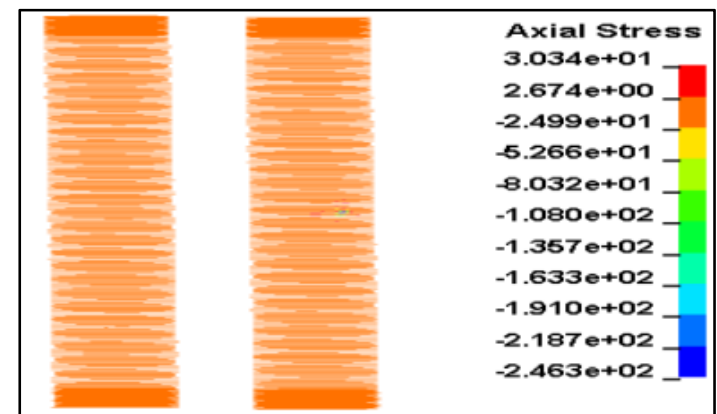

(a) $\mathrm{t}=3 \mathrm{~ms}$

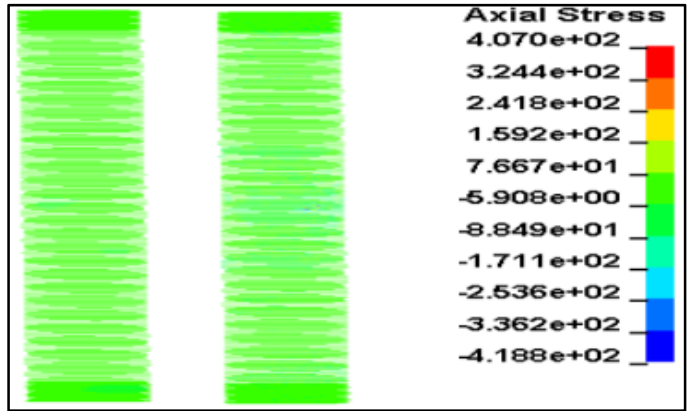

(b) $\mathrm{t}=15 \mathrm{~ms}$

Fig.9. Stress Nephogram of Stirrups in Bridge Pier under Basic Working Conditions

As shown in Fig.8, the longitudinal bar stress at the impact part of bridge pier changed and experienced the stress concentration phenomenon at $\mathrm{t}=3 \mathrm{~ms}$. The maximum longitudinal stress appeared at the impact part with the maximum stress value of $49.1 \mathrm{MPa}$, and the longitudinal bars in the bridge pier did not reach the yield strength, being under the elastic phase. The longitudinal wave stress at the impact part started diffusing around due to the stress wave transmission. At $\mathrm{t}=4 \mathrm{~ms}$, the stress concentration phenomenon appeared at the back, upper edge, and lower edge of the impact part of longitudinal bars in the bridge pier. At $t=10$ $\mathrm{ms}$, the longitudinal bars reached the maximum stress of 
Wu Liming, Zhang Jianing, Wang Zijian, Jiang Yi and Yuan Shifeng/

Journal of Engineering Science and Technology Review 14 (2) (2021) 34 - 43

309.368 MPa, which was extremely close to the yield strength of longitudinal bars. However, this condition still indicated that the longitudinal bars were in the elastic phase. As shown in Fig.9, at $\mathrm{t}=3 \mathrm{~ms}$, the stirrup stress at the impact part of bridge pier changed and concentrated, and the maximum stirrup stress (30.34 $\mathrm{MPa})$ appeared at the impact part. With the passing of time, the stirrup stress at the impact part continuously increased. At $\mathrm{t}=15 \mathrm{~ms}$, the stirrup stress reached the maximum value of $406.977 \mathrm{MPa}$ at the impact part, exceeding the yield strength of stirrups, which were no longer in the elastic phase.

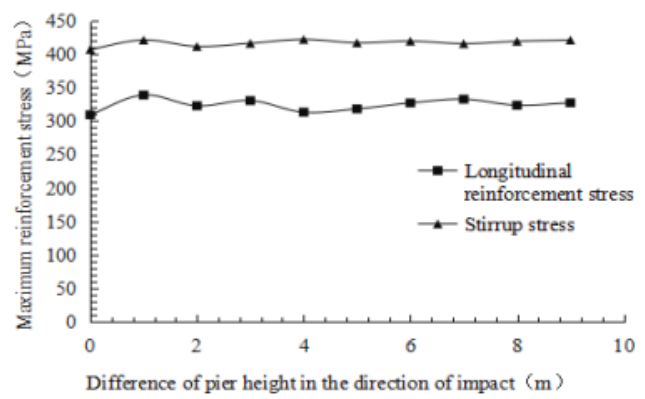

(a)
On the basis of the above analysis, the maximum stresses of longitudinal bars and stirrups appeared at the impact part under the impact of rolling stones, that is, the impact part of reinforcements was influenced to the greatest extent. Therefore, the emphasis should be laid on the maximum reinforcement stress in this study.

The variation diagram of maximum reinforcement stress in bridge piers under different pier height differences is shown in Fig.10. Table.5 and Table.6 present the maximum reinforcement stress values in bridge piers under different pier height differences.

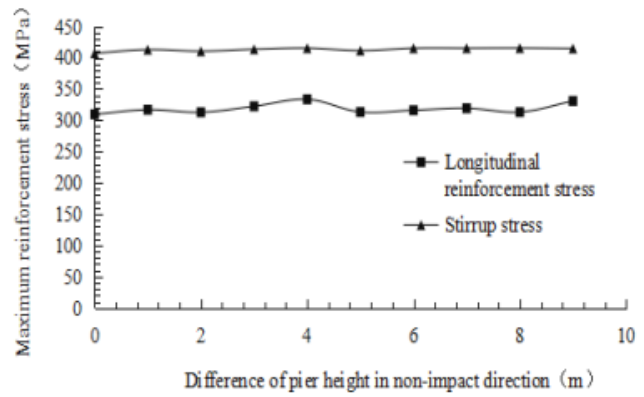

(b)

Fig.10. Variation Diagram of Reinforcement Stress under Different Pier Height Differences

Table 5. Bridge pier reinforcement stress table under the impact direction of pier height difference condition

\begin{tabular}{c|c|c}
\hline Height of pier & \multicolumn{2}{|c}{ Bridge pier reinforcement stress (MPa) } \\
\cline { 2 - 3 } The name of the & Longitudinal reinforcement stress & Stirrup stress \\
\hline 0 & 309.368 & 406.977 \\
1 & 338.809 & 421.036 \\
3 & 322.751 & 411.511 \\
4 & 330.532 & 416.183 \\
5 & 313.129 & 422 \\
6 & 318.16 & 416.872 \\
7 & 327.01 & 419.413 \\
8 & 332.637 & 415.684 \\
9 & 323.563 & 419.196 \\
\end{tabular}

Table 6. Bridge pier reinforcement stress under the condition of constant height difference in nonimpact direction

\begin{tabular}{c|c|c}
\hline $\begin{array}{c}\text { Height of pier } \\
\text { The name of the }\end{array}$ & Longitudinal reinforcement stress \\
\cline { 2 - 3 } 1 & 309.368 & 406.977 \\
2 & 316.768 & 412.907 \\
3 & 312.702 & 410.337 \\
4 & 322.263 & 413.517 \\
5 & 333.361 & 415.282 \\
6 & 313.141 & 411.329 \\
7 & 315.937 & 415.123 \\
8 & 319.138 & 415.258 \\
9 & 312.998 & 415.434 \\
\end{tabular}

As shown in Fig. 10, Table.5 and 6, the longitudinal reinforcement stress of bridge pier was $309.368 \mathrm{MPa}$, and the stirrup stress was $406.977 \mathrm{MPa}$ under the pier height difference of $0 \mathrm{~m}$. Under the pier height difference of $1 \mathrm{~m}$ in the impact direction, the longitudinal reinforcement and stirrup stresses in the bridge pier were 338.809 and 421.036 $\mathrm{MPa}$, respectively. Those in the bridge pier under the pier height difference of $1 \mathrm{~m}$ in the nonimpact direction were 316.768 and $412.907 \mathrm{MPa}$, respectively. Therefore, the pier height difference generated an adverse influence on the reinforcement stress. Under the pier height difference in the impact direction, the longitudinal reinforcement and stirrup stresses presented irregular changes with the increase in the pier height difference. When the pier height difference was 1 $\mathrm{m}$ in the impact direction, the longitudinal reinforcement and stirrup stresses in the bridge pier reached the maximum values of 338.809 and $421.036 \mathrm{MPa}$, respectively. When the pier height difference was $4 \mathrm{~m}$ in the impact direction, the increase amplitudes of longitudinal reinforcement and stirrup stresses were the smallest relative to those under the pier height difference of $0 \mathrm{~m}$. That is, this pier height difference influenced the reinforcement stress to the minimum extent. Under the pier height difference in the nonimpact direction, the longitudinal reinforcement and stirrup stresses presented irregular changes with the increase in the pier height difference. Specifically, the longitudinal reinforcement and stirrup stresses in the bridge pier reached the maximum values of $333.361 \mathrm{~m}$ and $415.282 \mathrm{MPa}$, respectively, when the pier height difference was $4 \mathrm{~m}$ in the nonimpact direction. Under the pier height difference of $2 \mathrm{~m}$ 
in the nonimpact direction, the longitudinal reinforcement and stirrup stresses in the bridge pier increased to the minimum extent relative to those under the pier height difference of 0 , that is, the influencing degree generated on the reinforcement stress was the slightest.

The impact degree of rolling stones on the pier reinforcement was high when the height difference of double-column high piers was singular. Thus, the pier height difference should be kept at 0 as much as possible in the design. Limited by the geological conditions, the impact degree was mild under an even height difference value between double-column high piers.

\subsection{Joint displacement analysis at pier top}

The time history curve of joint (1097277 joint) displacement at pier top and that of joint (1250519 joint) displacement at the impact part under the pier height differences in the impact direction and nonimpact direction are shown in Fig.11 and Fig.12, respectively, to study the influence of pier height difference on the joint displacement at critical parts.

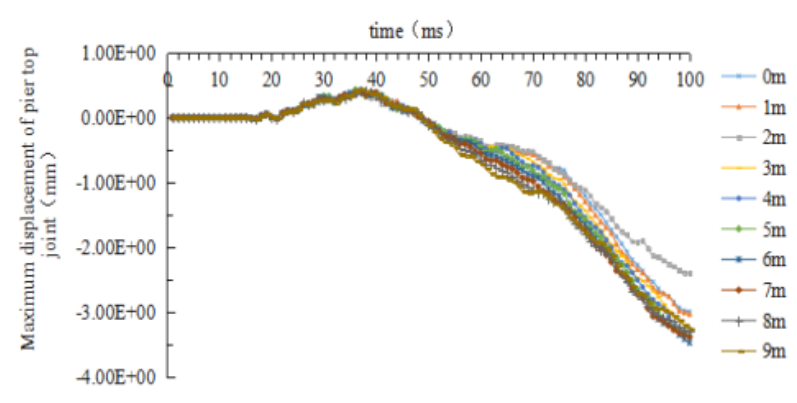

Fig.11. Time History Curves of Joint (1097277 Joint) at Pier Top under the Height Pier Differences in the Impact Direction

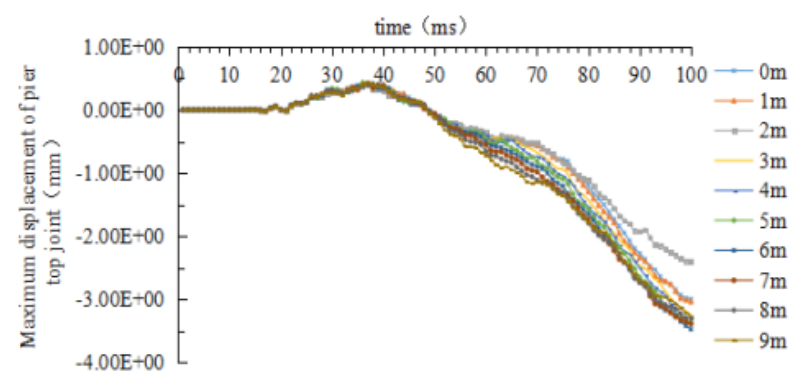

Fig. 12.Time History Curves of Joint (1097277 Joint) at Pier Top under the Height Pier Differences in the Nonimpact Direction

As shown in Fig.11 and Fig.12, the variation trends of joint displacement at pier top were relatively close under different pier height differences. These trends were increasing to the maximum displacement values first toward the reverse direction of the impact direction and then continuously increasing toward the same direction as the impact direction until reaching the maximum displacement values.

As shown in Table.7, with the increase in the pier height difference in the impact direction, the maximum joint displacements at pier top were $3.0347,3.03764,3.1133$, $3.2271,3.2761,3.4414,3.5300,3.5974,3.5847$, and 3.3885 $\mathrm{mm}$. Specifically, the maximum joint displacement at pier top increased with the increase in the pier height difference in the impact direction. The pier top growth rate gradually increased first and then declined with the increase in the pier height difference. With the increase in the pier height difference in the nonimpact direction, the maximum joint displacements at pier top were 3.0347, 3.111, 3.281, 3.331, $3.481,3.507,3.419,3.3289,-3.286$, and $3.035 \mathrm{~mm}$. Thus, the maximum joint displacement at pier top gradually enlarged first and then reduced with the increase in the pier height difference in the nonimpact direction.

Table 7. Maximum displacement of pier top nodes under different pier height differences (unit: $\mathrm{mm}$ )

\begin{tabular}{c|c|c|c|c}
\hline \multirow{2}{*}{$\begin{array}{c}\text { Height of pier } \\
\text { location }\end{array}$} & \multicolumn{2}{|c|}{ Impact direction } & \multicolumn{2}{c}{ Nonimpact direction } \\
\cline { 2 - 4 } & Y forward, & -3.0347 & \multicolumn{2}{c}{ Y forward, } \\
\hline $\mathrm{m}$ & 0.396 & -3.0764 & 0.396 & 0.397 \\
$2 \mathrm{~m}$ & 0.3908 & -3.1133 & 0.422 & -3.0347 \\
$3 \mathrm{~m}$ & 0.4072 & -3.2271 & 0.411 & -3.281 \\
$4 \mathrm{~m}$ & 0.4131 & -3.2761 & 0.434 & -3.331 \\
$5 \mathrm{~m}$ & 0.4214 & -3.4414 & 0.431 & -3.481 \\
$6 \mathrm{~m}$ & 0.4094 & -3.5300 & 0.402 & -3.507 \\
$7 \mathrm{~m}$ & 0.4124 & -3.5974 & 0.408 & -3.3289 \\
$8 \mathrm{~m}$ & 0.4158 & -3.5847 & -3.286 & -3.035 \\
\hline $\mathrm{m}$ & 0.4004 & -3.3885 & 0.456 \\
\hline
\end{tabular}

\section{Conclusions}

The stress changes in bridge pier structure and displacement changes at critical parts under the impact of rolling stones were analyzed through the finite element simulation to improve the anti-impact (rolling stones) performance of double-column high pier and ensure the safety of traffic line in mountain areas. The dynamic response of the pier structure under the impact of rolling stones at different positions and different initial velocities was compared and analyzed. The factors leading to the change in the dynamic response of bridge pier were expounded, and the following conclusions were mainly obtained.

(1) In the impact process of rolling stones on the doublecolumn high piers, the impact force of rolling stones reached the maximum value immediately after impacting the bridge pier concrete. The impact force rapidly declined to a small nonzero value after reaching the maximum value and then presented an oscillation variation trend with the compression of rolling stones and concrete due to the interaction between the rolling stones and bridge pier concrete. The impact force of rolling stones appearing in the oscillating variation phase was always smaller than that at the moment of impact. When the rolling stones no longer contacted the bridge pier concrete, the impact force became zero. Hence, focusing on the maximum impact force of rolling stones is necessary.

(2) Under the impact of rolling stones, the maximum stress values of longitudinal reinforcement and stirrups in the bridge pier appeared at the impact part, that is, the impact part of bridge pier reinforcement was influenced to 
the greatest extent. Therefore, the emphasis should be laid on the maximum reinforcement stress in this study.

(3) The bridge pier height difference generated an adverse effect on the reinforcement stress. With different pier height differences, the variation trends of joint displacements at pier top were relatively approximate. These trends were increasing to the maximum displacement toward the inverse direction of the impact direction and then continuously increasing toward the same direction as the impact direction until reaching the maximum value.

(4) With the increasing in the pier height difference in the impact direction, the maximum joint displacement at pier top enlarged, and its growth rate gradually elevated first and then lowered. The maximum joint displacement at pier top increased first and then reduced with the increase in the pier height difference in the nonimpact direction.

The impact born by the double-column high piers from rolling stones was simulated under varying pier height difference. The stress changes in bridge piers and reinforcement were observed extremely well through the simulation, which was an easy operation, thereby laying a foundation for further analyzing the dynamic response of bridge piers to the impact of rolling stones under complicated working conditions. However, the material of rolling stones used in this study was a rigid model. Although the calculation result had certain safety, the dynamic response calculation value of pier was larger than that of actual project. Further studying the selection of material model for rolling stones and the value selection of material parameters are necessary. Therefore, the working conditions of rolling stones will be enriched in the follow-up study to contribute to the deep understanding of the mechanical response of double-column high bridge piers to the impact of rolling stones in mountain areas.

\section{Acknowledgements}

The authors are grateful for the support provided by the Science and Technology Research Project of Chongqing Education Commission (Grant Nos.KJQN201804010 and KJQN202004004) and the research foundation of Chongqing Radio \& TV University(Chongqing Technology and Business Institute) (Grant No. NDZD2019-01).

This is an Open Access article distributed under the terms of the Creative Commons Attribution License.

\section{References}

1. Su, Y., "Study on the Collision Effect of the Rolling Stone to High Hollow Thin-Walled Pier". Master thesis of Southwest University of Science and Technology, China, 2016, pp.1-35.

2. Xiao, L, Z., "Research on the Impact of Mountain Rolling Stone on the Pier and Its Reinforcement". Master thesis of Southwest Jiaotong University, China, 2017, pp.10-30.

3. Wu, B., Yan, X, P., "Fuzzy logic based approach for ship-bridge collision alert system". Ocean Engineering, 187(9), 2019, pp.283297.

4. Zheng, Q, F., Han, B, G., Qu, J, P., "Ship-bridge collision monitoring system based on flexible quantum tunneling composite with cushioning capability". Smart Materials and Structures, 27(7), 2018, pp. 9-20.

5. Sha, Y, Y., "Dynamic responses of a floating bridge subjected to ship collision load on bridge girders". Procedia Engineering, 199, 2017, pp. 2506-2513.

6. Shao, J, H., Zhao, R, D., "Probabilistic Analysis of Bridge Collapse during Ship Collisions Based on Reliability Theory". Journal of Highway and Transportation Research and Development (English Edition), 9(1), 2015, pp.8-35

7. Shi, C, J., Wang, J, Q., "Design and research of bridge anti-vehicle collision device based on stiffness matching". Materials Science and Engineering, 439(4), 2018, pp.6-20.

8. Edouard, B., Charles, P, L., Nathalie, R., "Finite element modeling of the impact of heavy vehicles on highway and pedestrian bridge decks". Procedia Engineering, 199, 2017, pp.1845-1861.

9. Shahriari, M, H., Saeidi, G, H., "Prediction of vehicle impact speed based on the post-cracking behavior of automotive PVB laminated glass: Analytical modeling and numerical cohesive zone modeling”. Engineering Fracture Mechanics, 240, 2020, pp.1-80.

10. John, R., "Pier collision protection at Tay Road Bridge, Scotland". Proceedings of the Institution of Civil Engineers-Bridge Engineering, 167(3), 2014, pp.13-40.

11. Jing, G., Chao, J., Guo, J, Y., "Preparation and Research on a Kind of Magnetorheological Grease Materiel Used Anti-Collision System". Materials Science Forum, 4440, 2017, pp.395-399.

12. Petr, K., "Modelling the Tensile Softening Behavior of Concrete in LS-Dyna Software". Materials Science and Engineering, 960(4), 2020, pp.7-32.

13. Leidinger, L, F., Breitenberger, M., Bauer, A, M., "Explicit dynamic is geometric B-Rep analysis of penalty-coupled trimmed NURBS shells". Computer Methods in Applied Mechanics and Engineering, 351, 2019, pp.37-80.
14. Stolle, C, S., Bielenberg, R, W., "Large-radius curved guardrail installations for intersecting roadways". Journal of Transportation Safety \& Security, 11(3), 2019, pp.26-50.

15. Chahardoli, S., Alavi, A, N., "Parametric investigation of the mechanical behavior of expanding-folding absorbers and their implementation in sandwich panel's core". Thin-Walled Structures, 137, 2019, pp.14-50.

16. Ai, Y, B., Lu, M., "Optimization Design for Detonation Powerplant Based on LS-DYNA Simulation." Mathematical Problems in Engineering, 2016, pp.12-30.

17. Kee, P, J., "Impact crashworthiness of a floating offshore nuclear power plant hull structure in a terrorist attack with an aircraft strike". Ships and Offshore Structures, 15(1), 2021, pp.14-31.

18. Lu, Y., Shi, M, L., Dai, H., "Rolling Stone under the Action of the Numerical Simulation Research Shed Hole". Advanced Materials Research, 1270, 2011, pp.238-241.

19. Yang, Q, X., Guan, B, S., "Experimental study on calculation method of rock fall impact force". Journal of the China Railway Society, (01), 1996, pp.101-106.

20. Kawahara, S., Muro, T., "Effects of dry density and thickness of sandy soil on impact response due to rock fall". Journal of Terramechanics, 43(3), 2005, pp.29-340.

21. Derrick, D., "Impacted Rock Dynamics: A Case Study". Journal of Impacted Rock Science and Engineering, 81 (1), 1994, pp. 1-10.

22. Ye, S, Q., Chen, H, K., "Comparative study on calculation methods of rock fall impact". Hydrogeology and Engineering Quality, 37(02), 2010, pp.59-64.

23. Hou, T, X., Yang, X, G., "Calculation method of impact force of rolling stone on structure based on impulse theorem". Journal of Rock Mechanics and Engineering, 34(1), 2015, pp.3116-3122.

24. Richie, A, M., "Evaluation of rock fall and its control". Highway Research Record, (17), 1963, pp.13-18.

25. Lorentiz, J., Donz, F, V., "Experimental study of the dissipative efficiency of a multilayered protective structure against rock fall impact". Revue Europeenne Degenie Civil, 10(3), 2006, pp.295-308.

26. Mavrouli, O., Giannopoulos, P, G., "Damage analysis of masonry structures subjected to rockfalls". Landslides, 14(3), 2017.pp.14-28.

27. Anna, E., Anna, G., "Numerical Investigation of Rock fall Impacts on Muck piles for Underground Portal". Rock Mechanics and Rock Engineering, 50(6), 2017, pp.15-30.

28. Guo, S., Guo, Y, K., "Dynamic Response Analysis of Rolling Rock Impacting Double-Column Bridge Pier Based on Pile-Soil Interaction". Journal of Yan Cheng Institute of technology (Natural Science Edition). 32(02), 2019, pp. 66-73. 
Wu Liming, Zhang Jianing, Wang Zijian, Jiang Yi and Yuan Shifeng/

Journal of Engineering Science and Technology Review 14 (2) (2021) 34 - 43

29. Li, X, M., Han, J, M., "Numerical Simulation Analysis of Impact between Rolling Stone and Bridge Pier". Journal of Chongqing Jiaotong University (Natural Science Edition), 30 (05), 2011, pp.934-937.

30. Wu, Y., He, S, M., Li, X, P., "Research on the double-cavity elliptical eccentric wrap structure of the piers in mountainous areas against the impact of rolling stones". Engineering Mechanicsh, 34(10), 2017, pp.158-167.

31. Zhang, W, Q., Niu, Y, H., "Numerical simulations on cutting of frozen soil using HJC Model". Sciences in Cold and Arid Regions,

12(03), 2020, pp.134-143.

32. An, H, M., Liu, L., "Numerical Study of Dynamic Behaviors of Concrete under Various Strain Rates". Archives of Civil Engineering,65(4), 2019, pp.1-50.
33. Xiao, H, L., "Influence Factors Analysis of RC Beams under Falling Weight Impact Based on HJC Model”. Shock and Vibration, 2018, pp.16-32.

34. Gordon, J., Timothy, H., Charles, G., "Strain-rate effects associated with the HJC concrete model". EPJ Web of Conferences, 183, 2018, pp.1-95.

35. Polanco, L, M., "Numerical predictions of ballistic limits for concrete slabs using a modified version of the HJC concrete model". International Journal of Impact Engineering, 35(5), 2007, pp.9-65.

36. Han, G, G., "A tensile criterion to minimize FE mesh-dependency in concrete beams under blast loading". Computers and Concrete, 20(1),2017, pp.15-66. 